\title{
RIEOnLIFE: uma rede para potencializar a emergência de uma educação onlife
}

\author{
Eliane Schlemmer ${ }^{1}$ \\ Ana Maria Marques Palagi ${ }^{2}$
}

\section{RESUMO}

Como saber quais foram os principais problemas encontrados; quais as estratégias desenvolvidas em diferentes países, municípios, estados; e como se mobilizaram em tempos de pandemia da COVID-19? Como os estudantes, pais, professores, gestores e pesquisadores compreenderam esse movimento? Que aprendizagens e desafios a pandemia trouxeram à pesquisa em Educação? A partir dessas problematizações emerge a Rede Internacional de Educação OnLIFE (RIEOnLIFE), em parceria com a UAb Portugal. Este artigo objetiva apresentar o conceito de Educação OnLIFE, a RIEOnLIFE e seus movimentos, bem como discutir o primeiro movimento da rede, o Movimento EscutAÇÕES. De natureza qualitativa, a pesquisa busca inspiração no conceito de Living Labs, articulado ao método cartográfico de pesquisa- intervenção, originando três movimentos como território da pesquisa: as escutAÇÕES, as COnversAÇÕES e as COMpartilhAÇÕES. Os resultados evidenciam potência para: conectar instituições e sujeitos; compreender os problemas, estratégias e movimentos; conhecer desafios e aprendizagens; constituir um espaço comum de legitimação e construção da RIEOnLIFE enquanto rede ou plataforma de Educação OnLIFE.

Palavras-chave: Educação na Pandemia. Educação OnLIFE. Rede RIEoNLIFE.

\footnotetext{
${ }^{1}$ elianeschlemmer@gmail.com - Universidade Vale do Rio dos Sinos - UNISINOS 2 marquespalagi@gmail.com - Secretaria Estadual de Educação do Paraná - SEED
} 


\section{RIEOnLIFE: a network for development of onlife education}

\section{ABSTRACT}

How to know what were the main problems found, what strategies were developed in different countries, cities and states, how they mobilized in times of the COVID-19 pandemic? How did students, parents, teachers, administrators and researchers understand this movement? What lessons and challenges did the pandemic bring to research in Education? From these problematizations, RIEOnLIFE emerges, in partnership with the UAb Portugal. This article aims to present the concept of OnLIFE Education, RIEOnLIFE and its movements, as well as discuss the network's first movement, escutAÇÕES. From qualitative origen, it appropriates the concept of Living Labs, articulated with the cartographic method of intervention research, giving rise to three movements as research territory: the escutAÇÕES (listening action), the COnversAÇÕES conversations action - and the COMpartilhAÇÕES - sharing's actions. Preliminary results indicate power to: connect the subjects involved; to understand the issues raised, strategies and movements; get to know challenges and learnings; to constitute a common space for the legitimization and construction of RIEOnLIFE as an OnLIFE Education network or platform.

Keywords: OnLIFE Education. Network. RIEOnLIFE. 
A presença de tecnologias digitais (TD) em rede se faz cada vez mais intensa em todos os domínios da sociedade e vem provocando transformações significativas que alteram modos de operar. Essas tecnologias adquirem ainda maior importância no contexto pandêmico que estamos vivendo ou no "pós-pandêmico" que viveremos. Apesar disso, na Educação, o que presenciamos nos últimos 30 anos foi a incorporação dessas tecnologias em rede ao modo secular de operar das instituições formais e, além do mais, num ritmo extremamente lento, o qual só foi acelerado agora, em função da pandemia.

Para além dessa questão, façamos a seguinte análise: a COVID-19, doença causada por um vírus, este uma entidade não humana invisível a olho nu, o que exige, portanto, outra entidade não humana - a tecnologia - para ser identificado, analisado, compreendido, transformou por completo as nossas vidas devido à sua ação sobre nós e sobre o mundo, colocando-nos em isolamento físico. Nesse cenário, foi novamente outra entidade não humana, a TD em rede, que evitou o isolamento social, ao possibilitar, por sua funcionalidade, que continuássemos nos comunicando, interagindo, estudando e trabalhando, viabilizando, assim, a retomada de um viver e conviver, ainda que com restrições ao deslocamento físico no espaço geográfico. 0 que podemos aprender com isso?

Isso nos indica que, além da transformação no modo de operar de diferentes domínios da sociedade, os quais já vinham sendo provocados pelas TD em rede antes da pandemia, a partir desta, torna-se ainda mais evidente que o humano não é a única entidade que possui ação neste mundo e também não é o centro, mas sim um comembro nessa teia da vida. Dessa maneira, a pandemia problematizou a nossa visão antropocêntrica do mundo, a qual nos mantêm numa relação de uso, de exploração como algo que nos serve, com tudo o que não é humano. Esse despertar da consciência tem implicações ainda mais profundas no campo da Educação, uma vez que não se trata mais de somente transformar o modo de operar, mas a forma de conceber a própria Educação, compreendendo o humano não como centro, mas como um comembro em rede conectiva com o mundo, com a vida, com o planeta, num processo de afetação mútua, transubstanciado pelas TD.

$\mathrm{Na}$ pandemia, presenciamos muitas instituições com alto nível de comprometimento social, mobilizando-se, buscando soluções e reinventando-se na medida das suas limitações. Outras, por sua vez, fazendo uso de argumentos relacionados à falta de acesso às TD e à conexão em rede - problemas esses também enfrentado por instituições que encontraram formas de continuar a cumprir sua função social, mesmo num contexto tão adverso - paralisaram totalmente suas atividades, deixando de construir alternativas que possibilitassem aos estudantes dar continuidade aos seus estudos e, por consequência, negligenciando a própria função na sociedade.

Dessa forma, foram as TD em rede, com suas diferentes plataformas, que oportunizaram a continuidade dos processos de ensino e de aprendizagem, evitando que milhares de estudantes ficassem sem acesso à educação formal. Esses estudantes e professores, nesse período, 
deslocaram-se no espaço digital, explorando, experienciando diferentes plataformas e novos habitares do ensinar e do aprender, fato esse que pode potenciar inovações na educação.

Tal contexto nos instiga às seguintes questões: quais foram os principais problemas encontrados, bem como quais foram as estratégias desenvolvidas em diferentes países e, principalmente, no Brasil, a fim de dar continuidade à educação em tempos de pandemia? Como os municípios, os Estados e as universidades brasileiras se mobilizaram? Como os estudantes, pais, professores, gestores e pesquisadores compreenderam esse movimento? Que aprendizagens e desafios a pandemia trouxeram para a pesquisa em Educação? A partir dessas problematizações, e no âmbito da pesquisa Transformação Digital na Educação: ecossistemas de inovação em contexto híbrido e multimodal', emerge, como uma das ações de pesquisa em educação em tempos de pandemia, a Rede Internacional de Educação OnLIFE (RIEOnLIFE)ii.

O objetivo deste artigo, então, é apresentar a RIEOnLIFE e seus movimentos, assim como discutir o processo de construção, desenvolvimento e alguns resultados de um dos movimentos da rede, o Movimento EscutAÇÕES.

Após essa breve contextualização, e com o objetivo acima referido, o artigo é organizado nas seguintes sessões: apresentação breve do conceito de Educação OnLIFE; apresentação da constituição da Rede Internacional de Educação OnLIFE e seus movimentos; descrição do Método da pesquisa; discussão das Conexões e Resultados Preliminares do Movimento EscutAÇÕES; e Considerações Finais.

\section{EDUCAÇÃO OnLIFE: UM CONCEITO EM CONSTRUÇÃO}

O conceito de Educação OnLIFE, embora tenha ganhado visibilidade na Educação em tempos de pandemia e "pós-pandemia", é resultado de um processo de construção que tem origem na tríade conectiva pesquisa-desenvolvimento-formação que se desenvolve no contexto do Grupo Internacional de Pesquisa Educação Digital (Gpe-dU UNISINOS) iii. A rede conceitual e de desenvolvimento tecnológica digital que constitui o conceito de Educação OnLIFE é apresentada na Figura 1.

O percurso que constitui a tríade pesquisa-desenvolvimento-formação resultou, em 2005, na construção do conceito de hibridismo tecnológico digital, o qual posteriormente evoluiu para a tecnologia-conceito Espaço de Convivência Digital Virtual (ECODI) ${ }^{\text {iv }}$ e para a tecnologia-conceito Espaço de Convivência e Aprendizagem Híbrido e Multimodal (ECAHiM)v , dando origem ao conceito de Educação Híbrida e Multimodalvi. Nesse percurso de construção, diferentes elementos teórico-epistemológico-metodológicos e tecnológicos foram fornecendo pistas sobre o processo do desenvolvimento e amadurecimento, o que resulta no conceito de Educação OnLIFE, ainda em elaboração.

Mais especificamente, o conceito de Educação OnLIFE emerge no âmbito da Educação Digital e amplia a compreensão de Educação Híbrida e Multimodal, levando consigo (1) as epistemologias reticulares e conectivas vii, articuladas à perspectiva da (2) cognição inventivaviii a elementos do (3) método cartográfico de pesquisa-intervenção ${ }^{i x}$, principalmente, no que se refere aos movimentos da atenção do cartógrafo, a metáfora das pistas e (4) da gamificação, enquanto empoderamento. Essas dão origem às metodologias e práticas pedagógicas inventivas ${ }^{x}$. A essa 
construção epistemológica-teórica-metodológica estão vinculados diferentes desenvolvimentos tecnológicos digitais, tais como o ARG Fantasma no Museu, o Mobile, Ubiquitous, Pervasive Extended Reality Gamification (MUP-ERG) In Vino Veritas e o MUP-ERG Ágora do Saber.

\section{Figura 1 - Rede conceitual e tecnológica que dá origem ao conceito Educação OnLIFE}

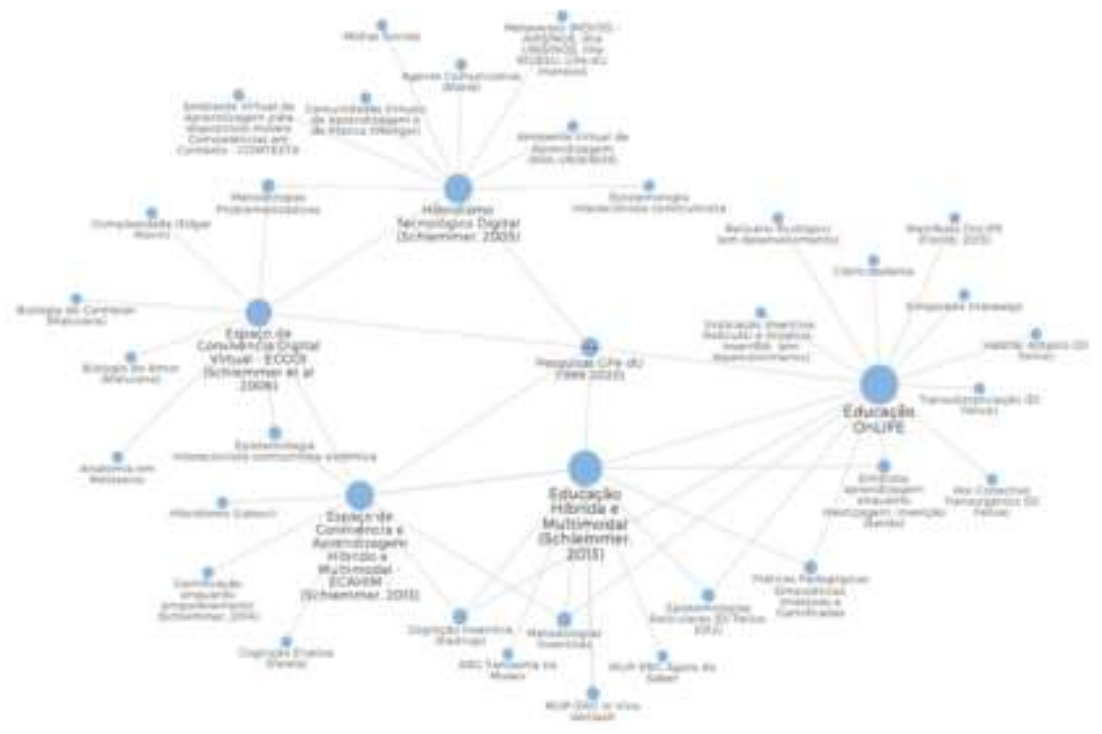

\section{Fonte: Schlemmer (2020).}

O percurso dessa construção, associado a processos formativos em diferentes níveis, nos quais foram validadas as metodologias e práticas criadas, evidenciou, enquanto estavam sendo desenvolvidos, a necessidade de novos conceitos. Assim, encontramos nos conceitos de simbiota e aprendizagem, enquanto mestiçagem: invenção (SERRES, 1990; 1994; 2013; 2010; 2017); ato conectivo transorgânico, transubstanciação; habitar atópico (DI FELICE 2009; 2017), onlife (FLORIDI, 2015); hipercomplexidade (MORIN, 2011); simpoiesis (DONNA HARAWAY, 2014; HARAWAY, 2015, 2016a, 2016b). Tais elementos contribuem para que possamos melhor compreender os novos habitares do ensinar e do aprender nessa realidade hiperconectada. Esse conhecimento, por sua vez, está subsidiando o desenvolvimento das plataformas de interação ecológica (SCHLEMMER; DI FELICE, 2020) denominadas: Relicário Ecológico e Instalação Inventiva, Reticular e Atópica (Inven!RA), ambas em desenvolvimento no contexto do Projeto Capes Print Transformação Digital e Humanidades, financiado pela Capes, que envolve universidades de Portugal, Itália, França, Espanha, Alemanha e Estados Unidos.

Dessa forma, o conceito de Educação OnLIFE vem se constituindo, e pistas sobre esse processo vem sendo explicitadas por Schlemmer (2020), Moreira e Schlemmer (2020), Schlemmer, Di Felice e Serra (2020), Schlemmer e Moreira (2020), Schlemmer, Oliveira e Menezes (2020). Essas pistas podem auxiliar: na compreensão da virtualidade de uma Educação OnLIFE; na identificação de alterações significativas que precisam ser realizadas no paradigma educacional a fim de que essa educação possa emergir e, portanto, atualizar-se e; no entendimento do que se altera em relação aos processos de ensino e de aprendizagem nesse contexto.

Schlemmer, Di Felice e Serra (2020) referem que a realidade hiperconectada - resultante da hibridização do mundo físico, do mundo biológico e do mundo digital; as experiências 
educacionais vivenciadas durante a pandemia e, mais recentemente, em alguns países no que tem sido chamado de "pós-pandemia"; os questionamentos que se originam dessas vivências vem se constituindo num território fértil para a construção de uma Educação OnLIFE.

De acordo com Schlemmer, Oliveira e Menezes (2020), a Educação OnLIFE compreende: (a) as TD em rede, compreendidas enquanto "forças ambientais"(FLORIDI, 2015), que no campo da educação modificam professores e estudantes, a sua forma de interação, alterando os processos de ensino e de aprendizagem, bem como a compreensão da realidade e as formas como se conectam com essa realidade. Nesse contexto, as TD deixam de ser compreendidas enquanto ferramentas, instrumentos, recursos, apoio a serem usados na Educação ou, ainda, enquanto tecnologias da inteligência a serem apropriadas pelo humano e passam a ser compreendidas como potência para a emergência de ecologias inteligentes (DI FELICE, 2017), de ecossistemas educativos que afetam a forma como ensinamos e como aprendemos; (b) a rede como um novo tipo de hipercomplexidade ecossistêmica (MORIN, 2011), que é sempre um conjunto de redes de redes, isto é, um conjunto de inter-relações, cujos limites ou perímetros são ilimitados e remetem, sobretudo, a entidades humanas e não humanas (DI FELICE, 2020); (c) as plataformas de interação ecológica ou ainda as plataformas ecossistêmicas conectivas inventivas (SCHLEMMER; DI FELICE, 2020), constituindo um novo tipo de habitar; (d) a educação como ligada, conectada - On -, instigada pelas problematizações da vida - LIFE - no tempo presente, num contexto de aprendizagem inventiva (KASTRUP, 2001, 2015), potencializada pelas ecologias inteligentes; (e) uma arquitetura ecossistêmica conectiva - humanos, máquinas e natureza -, que possibilita um habitar atópico do ensinar e do aprender, que busca a superação de uma compreensão de mundo antropocêntrica, sujeitocêntrica e antropomórfica.

É a combinação da (1) problematização do tempo presente, nessa nova realidade hiperconectada, com suas (2) TD, em rede, compreendidas enquanto forças ambientais; e (3) o processo de digitalização do mundo, que têm tensionado as epistemologias, teorias, metodologias e práticas pedagógicas, problematizando as pedagogias vigentes. Pedagogias essas, que não conseguem abranger a hipercomplexidade presente nessa realidade hiperconectada, uma vez que limitam o agir apenas aos humanos, numa visão antropocêntrica do mundo.

A fim de sistematizar, Schlemmer (2020) refere que é essa realidade educacional hiperconectada, que potencia a Educação OnLIFE. Uma educação ligada, conectada - On - na vida - LIFE -, a partir das problematizações do mundo e tempo presente, o que instiga a inventividade. Nesse contexto, as TD em rede são compreendidas enquanto forças ambientais (FLORIDI, 2015), as quais provocam alterações no campo da educação, não somente vinculadas à estrutura física, espaço-temporal, mas também tem a potência de transformar a própria arquitetura educacional, o currículo, as metodologias, as práticas, os conteúdos, as pedagogias. Dessa forma, entende-se que o processo de digitalização e a conectividade tem a potência de alterar qualitativamente o estatuto da natureza e da condição habitativa dos processos de ensinar e do aprender, ou seja, a educação sofreria então um processo de transubstanciação (DI FELICE, 2017) e não de transposição - transferir, mudar de lugar - como fora percebido durante o período de pandemia. 
Assim, entende-se por Educação OnLIFE, uma educação transubstanciada e cibricidadãxi, ligada, conectada na vida, a partir de problematizações que emergem do tempo presente, nessa realidade hiperconectada. Implica, portanto, uma perspectiva ecológica complexa e conectiva, na qual a própria substância das materialidades de espaços, conteúdos, práticas e sujeitos é alterada para dados (PIRES, 2016). Isso não significa, no entanto, que esses elementos percam suas substâncias originais, mas sim que, pela digitalização, sofrem um processo de transubstanciação, que nos instiga a inventividade, em composições híbridas para o desenvolvimento sustentável e transformação social, num contexto de cibricidade (SCHLEMMER, 2020).

O conceito de Educação OnLIFE coloca em evidência a necessidade dos processos de ensino e de aprendizagem habitarem novos territórios, superando tanto as teorias instrucionistas, cuja centralidade está no conteúdo e no professor - o que resulta numa pedagogia diretiva -, quanto à teoria da ação, centrada no sujeito - o que resulta numa pedagogia ativa - e, consequentemente, em metodologias e práticas também conhecidas como ativas. Essa superação implica na compreensão dos processos de ensino e de aprendizagem a partir da lógica de redes, esta que no lugar de uma teoria instrucionista ou ativa, temos o ato conectivo (DI FELICE, 2017), produzido nas interações entre entidades humanas e não humanas que, ao entrarem em relação, expressam a dimensão transorgânica, impermanente e criadora. Com base nessa compreensão, não há centralidade no processo educacional, mas a construção de redes que, pela conectividade, possibilitam a conexão com outras redes, desenhando uma arquitetura ecossistêmica. Isso tem nos instigado a pensar e criar pedagogias relacionais, conectivas, em rede, capazes de produzir metodologias e práticas inventivas, num habitar atópico.

É nesse contexto, e do processo de construção que dele se origina, que emerge a Rede Internacional de Educação OnLIFE - RIEOnLIFE, apresentada a seguir.

\section{A REDE INTERNACIONAL DE EDUCAÇÃO OnLIFE E SEUS MOVIMENTOS}

A Rede Internacional de Educação OnLIFE é uma ação concebida em maio de 2020, pelo GPe-dU UNISINOS/CNPq, em parceria com a Universidade Aberta de Portugal e coordenada por mestres, doutores e pós-doutores, egressos do grupo de pesquisa e que hoje atuam em diferentes instituições e regiões do Brasil e no exterior. Essas instituições passam também a se conectar na Rede, além de outras que têm o desejo de compor conosco, uma vez que se trata de uma rede aberta.

A RIEOnLIFE surge pela necessidade de ouvir, discutir e refletir com pesquisadores, gestores, professores e estudantes de diferentes níveis de educação em contextos nacionais e internacionais sobre as compreensões, ações e proposições relacionadas à educação na contemporaneidade, principalmente, instigada pela pandemia, a fim de que possamos juntos, potencializar-nos enquanto rede que pensa e constrói uma Educação OnLIFE.

O objetivo principal da RIEOnLIFE consiste então em cocriar uma rede ou plataforma de Educação OnLIFE, que conecta pesquisadores, gestores, professores e estudantes, pais ou responsáveis para, a partir do conhecimento das diversas realidades educacionais brasileiras e internacionais, configurar um novo ecossistema conectivo de inovação na educação. 
Um primeiro movimento dessa rede consistiu em ouvir, por meio de lives nacionais e internacionais, bem como por entrevistas focadas, estudantes, pais, professores, gestores, pesquisadores e elaboradores de políticas públicas, contemplando, no contexto nacional, as secretarias estaduais de educação, a União Nacional dos Dirigentes Municipais de Educação (UNDIME) - representando as secretarias municipais de cada estado - e as universidades, com a finalidade de conhecer como a pesquisa tem se conectado com as diferentes realidades. Até o momento, foram realizadas 23 lives nacionais, contemplando as diferentes regiões do Brasil; 7 lives internacionais, com países da América, Europa, e Ásia; e mais de 19 entrevistas focadas, em profundidade, com o objetivo de compreender os movimentos da educação em tempos de pandemia segundo a visão dos diferentes atores acima referidos. As lives nacionais e internacionais, assim como as entrevistas, compõem a série Educação Digital em Rede em tempos de pandemia: diálogos nacionais e internacionais, constituindo o primeiro movimento da pesquisa no território, que foi o da escuta.

Nesse sentido, buscamos compreender, no âmbito das lives internacionais, como os países estão se movimentando no que se refere à Educação em tempos de pandemia e "póspandemia"? Que estratégias estão desenvolvendo em relação à Educação Digital em Rede? Quais os investimentos que estão sendo realizados para viabilizar a Educação Digital em rede? Como está sendo desenvolvida a formação docente? Que políticas públicas de educação e de formação docente estão sendo construídas? Como as famílias estão se movimentando? Qual a contribuição das universidades? Quais as principais dificuldades, desafios e aprendizagens propiciadas nesse período?

No âmbito das lives nacionais, buscamos compreender: como os municípios e o estado estão desenvolvendo a Educação Digital em Rede em tempos de pandemia? Quais são as estratégias adotadas pelos Estados e municípios? Quais são os investimentos? Como está sendo desenvolvida a formação docente? Que políticas públicas de educação e de formação docente estão sendo construídas? Como está se desenvolvendo a relação com as famílias? Qual a contribuição das universidades? Que articulações estão sendo realizadas? Como a pesquisa tem contribuído nesse momento? Quais as principais dificuldades, desafios e aprendizagens propiciadas nesse período?

Quanto às entrevistas, buscamos compreender: de onde os sujeitos falavam? Como foram organizadas as atividades educacionais na instituição? Quais foram as dificuldades encontradas neste período? No planejamento escolar, a escola considerou a estrutura existente, da escola e do aluno, quanto às TD? Na reorganização do planejamento, houve o recebimento adequado das orientações das instâncias superiores? Como foi o acompanhamento e a avaliação dos processos de ensino e aprendizagem? Como as TD se desenvolviam no cotidiano nos processos de ensino e de aprendizagem? Quais as maiores dificuldades deste período frente às atividades educacionais online? Após a pandemia, acredita-se em mudanças? Quais e de que natureza?

Paralelamente, a análise do material produzido, na qual já aponta alguns indícios, inicia-se um segundo movimento mais focado: o de COnversAÇÕES com especialistas, compondo a série COnversAÇÕES em Rede sobre Educação OnLIFE. O objetivo é compreender as estratégias adotadas estabelecendo relações com a pesquisa na área, a fim de que possamos juntos pensar e construir movimentos de Educação OnLIFE. 
Nesse cenário, realizamos as seguintes sessões: COnversAÇÕES sobre o Habitar redes - os significados do conhecimento nas arquiteturas conectivas (com Massimo Di Felice); COnversAÇÕES sobre transformação digital e humanidades no tempo presente (com José António Marques Moreira, Maura Corcini Lopes, Ruth Contreras), COnversAÇÕES sobre O Habitar do Ensinar e Aprender na Cibricidade (com José António Marques Moreira, Luciana Backes e Eliane Schlemmer), COnversAÇÕES com Professores, COnversAÇÕES com Gestores e COnversAÇÕES com Kids and Teens (com os estudantes).

Da articulação entre os dois primeiros movimentos emerge um terceiro movimento, o das COMpartilhAÇÕES que compõe a série COMpartilhAÇÕES RIEOnLIFE. O objetivo é compartilhar ações de Educação OnLIFE para que possamos juntos potencializar-nos enquanto rede.

Nesse contexto, realizamos as seguintes sessões: COMpartilhAÇÕES ConeXões RIEOnLIFE; COMpartilhAÇÕES Educação OnLIFE no Stricto Sensu; COMpartilhAÇÕES Transformação Digital e Humanidades - Capes Print - e desenvolvimento da Plataforma InvenIRA; COMpartilhAÇÕES Alice no Labirinto da Aprendizagem: a prática pedagógica iMERGE - inventive iMmERsive Gamified Experience; COMpartilhAÇÕES Sucraft: educação digital para a cidadania; COMpartilhAÇÕES Portugal; COMpartilhAÇÕES Moçambique; e COMpartilhAÇÕES Kids and Teens (Brasil).

Estes dois movimentos: COnversAÇÕES e COMpartilhAÇÕES ocorreram no contexto do $V$ We Learning with the Cibricity - WLC2020: O Habitar do Ensinar e do Aprender OnLIFE, realizado nos dias 07 e 08 de dezembro de 2020; e do RIEOnLIFE2020: O Habitar do Ensinar e do Aprender OnLIFE, realizado nos dias 09 e 10 de dezembro de 2020.

O WLC2020 se constituiu enquanto espaço-tempo comum de convivência e COnversAÇõES, bem como de COMpartilhAÇÕES de diferentes atividades, realizadas por crianças, adolescentes e professores da Educação Básica, durante o ano pandêmico, no contexto da cibricidade, compreendida enquanto essa cidade que de uma geografia física se hibridiza, amplia-se e se potencializa para outras "geografias" digitais, informacionais.

O RIEOnLIFE2020 teve como objetivo discutir o habitar do ensinar e do aprender num mundo hiperconectado, segundo as problematizações do tempo presente, a fim de que pudéssemos nos potencializar enquanto rede na configuração de ecossistemas conectivos de inovação para a Educação OnLIFE.

Ainda, no âmbito das propostas de Educação OnLIFE, emerge do processo de cocriação na RIEOnLIFE, a ConectaKaT. A ConectaKaT é uma rede internacional que conecta crianças e adolescentes em diferentes lugares do mundo, potencializando o seu protagonismo inventivo, engajado e responsável na cocriação de vivências de uma Educação OnLIFE cidadã. Trata-se de uma ação criada em 01 de julho de 2020, coordenada por um grupo de crianças, adolescentes, pais, professores e pesquisadores de diferentes regiões do Brasil e que está sendo ampliada para o exterior. O objetivo da ConectaKaT é cocriar uma rede ou plataforma de vivências de Educação OnLIFE Cidadã, a partir do protagonismo e inventividade de crianças e adolescentes. Participam, atualmente, crianças e adolescentes de seis estados brasileiros. 
A pesquisa, de natureza qualitativa, constrói um percurso próprio, diferenciando-se da compreensão de método - do grego methodos; meta significa através de, por meio, e hodos significa caminho, via -, uma vez que método, tanto na perspectiva da história da filosofia quanto das ciências, tem o objetivo de regular o pensamento e as ações, aferindo e avaliando ideias e teorias, ou seja, o método guia o trabalho prático-intelectual e avalia os resultados obtidos. Assim, fazer uso de um método é pré-ordenar um trajeto a ser seguido, a partir de procedimentos ou meios, para que se possa alcançar objetivos planejados, isto é, trata-se de seguir um planejamento, um rumo.

Nesse sentido, a pesquisa se aproxima da compreensão de metodologia de acordo com o grego como "investigação científica, modo de perguntar," de instigar, ato de ir em busca. Segundo Passos e Barros (2012, p. 17) "primado do caminhar que traça, no percurso, suas metas", entendendo meta como reflexão, raciocínio, verdade. Nessa perspectiva, durante o percurso de investigação científica, o que existem são pistas que podem orientar o ato de ir em busca. É a partir dessa compreensão que entendemos que uma metodologia pode ser inventiva ao se aproximar da compreensão de metodologia, enquanto estudo do método, em outras palavras, o estudo dos caminhos para se chegar a um determinado fim.

Diante disso, inspiramo-nos no conceito de Living Labs proposto, na década de 90, por William J. Mitchell e no método cartográfico de pesquisa-intervenção, proposto por Passos, Kastrup e Escóssia (2009); Passos, Kastrup e Tedesco (2014) para o desenvolvimento da pesquisa.

A ideia principal do conceito de Living Labs é a cocriação de processos de pesquisa e inovação pelos participantes que habitam e coabitam determinado contexto territorial. No caso desta pesquisa, envolve os estudantes, pais ou responsáveis, professores, gestores e pesquisadores que estiveram ou estão conosco na RIEOnLIFE. Esse processo de cocriação implica uma equipe interdisciplinar e pode ocorrer em diferentes níveis do processo de pesquisa e inovação, desde a exploração, experimentação e avaliação de ideias emergentes, cenários inovadores e artefato até a participação efetiva na concepção, desenvolvimento, acompanhamento e a avaliação de uma ideia, conceito, artefato tecnológico.

O Living Labs é compreendido, então, como um ecossistema de inovação aberta, colaborativo e focado na interação, no âmbito da pesquisa público-privado - governo, academia, centros tecnológicos e empresas. Para esta pesquisa, integram esse ecossistema as universidades, secretarias de educação, redes de escolas de Educação Básica públicas e privadas, bem como espaços de relação entre universidade, escola, governo, empresa, ONGs, os quais irão, em diferentes momentos, ter algum tipo de participação no processo.

Dessa forma, o conceito de laboratórios vivos envolve os participantes e comunidade também enquanto atores no processo de criação do conhecimento, e não somente como observadores ou sujeitos da pesquisa. Assim, um laboratório vivo se constitui como um ambiente experiencial - experimental + vivencial -, no qual os participantes estão imersos em um espaço social criativo para conceber, projetar, acompanhar e avaliar o seu próprio futuro. Esse conceito está vinculado à mudança e transformação social; no caso desta pesquisa, na cocriação de uma rede ou plataforma de Educação OnLIFE, que conecta pesquisadores, gestores, professores, 
estudantes e famílias para, a partir do conhecimento das diversas realidades educacionais brasileiras e internacionais, configurar o novo ecossistema conectivo de inovação na educação.

O método cartográfico de pesquisa-intervenção (PASSOS; KASTRUP; ESCÓSSIA, 2009) e (PASSOS; KASTRUP; TEDESCO, 2014) propõe acompanhar um processo, no lugar de representar um objeto. Trata-se de investigar um processo de produção, sem buscar estabelecer um caminho linear para atingir um fim. A construção caso a caso não impede que se procure estabelecer algumas pistas que têm em vista descrever, discutir e, sobretudo, coletivizar a experiência do cartógrafo. Assim, no lugar de regras a serem aplicadas no método, Passos, Kastrup e Escóssia (2009, p. 13) sugerem pistas para orientar o trabalho do pesquisador-cartógrafo: "as pistas que guiam o cartógrafo são como referências que concorrem para a manutenção de uma atitude de abertura ao que vai se produzindo e de calibragem do caminhar no próprio percurso da pesquisa - o hódos-metá da pesquisa." A atenção cartográfica é definida como concentrada e aberta, caracterizando-se por quatro variedades: rastreio, toque, pouso e reconhecimento atento.

o rastreio, nesta pesquisa, se caracteriza pela exploração ou varredura do campo, composto pelo conjunto dos dados produzidos nos territórios. Consiste em um voo, cuja atenção é aberta e sem foco. Um olhar mais amplo em busca de pistas, algo que o toque, para além da busca de informação.

O toque aciona o processo de seleção das pistas para compor a pesquisa. Neste estudo, refere-se à primeira significação, à primeira análise realizada sobre o rastreio. É caracterizado por uma rápida sensação de foco na atenção quando algo toca, chama a atenção, fazendo-o entrar em estado de alerta, mas que ainda não define no que o pesquisador-cartógrafo focará. 0 movimento que se refere a um ponto definido da atenção - foco - é o pouso, que é a parada, zoom nas pistas, escolha, definição, indica que o elemento selecionado precisa ser olhado mais de perto para uma análise. Em outras palavras, "o gesto do pouso indica que a percepção, seja, ela visual, auditiva ou outra, realiza uma parada e o campo se fecha, numa espécie de zoom. Um novo território se forma, o campo de observação se reconfigura." (PASSOS; KASTRUP; ESCÓSIA, 2009, p. 43, grifo nosso). No contexto desta pesquisa, consiste nas pistas identificadas no toque que orientam o processo cocriação de uma rede ou plataforma de Educação OnLIFE.

O quarto e último movimento é o reconhecimento atento de Bergson (1999), que se caracteriza por uma atitude investigativa sobre o pouso, sobre o que chamou a atenção do pesquisador-cartógrafo. É a reconfiguração do território da observação. Representa a análise propriamente dita, aqui evidenciada pela cocriação de uma rede ou plataforma de Educação OnLIFE, configurando um novo ecossistema conectivo de inovação na educação.

O objetivo do pesquisador-cartógrafo é justamente cartografar um território que, em princípio, não habitava, compreender os planos de força - plano movente da realidade das coisas que nele atuam - e produzir conhecimento ao longo de um percurso de pesquisa, o que envolve a atenção e, com ela, a própria criação desse território de pesquisa-intervenção (ESCÓSSIA, TEDESCO, 2009). Assim sendo, por se tratar de pesquisa-intervenção, a análise se dá no processo, ou seja, no movimento da cartografia, o que possibilita realizar a intervenção enquanto o processo está ocorrendo.

Esse delineamento de pesquisa dá origem a três movimentos que constituem os territórios da pesquisa: as EscutAÇÕES, as COnversAÇÕES e as COMpartilhAÇÕES. Durante esses 
movimentos os dados são produzidos e analisados, fato que permite realizar intervenções durante o desenvolvimento da pesquisa.

No primeiro movimento da pesquisa, que corresponde às EscutAÇÕES - ou escuta atenta , os dispositivos compreendem as lives nacionais e internacionais, as entrevistas em vídeo ou áudio, bem como as interações realizadas no chat de cada live. No caso específico deste artigo, será analisado somente as lives nacionais.

Nestes movimentos, fomos buscando pistas relacionadas aos seguintes domínios: Estratégias; Desafios, Investimentos; Formação de Professores; Família; Articulação com a Universidade; Políticas Públicas; Aprendizagens, Educação pós-pandemia. Tais pistas nos permitem responder as principais questões que mobilizaram a emergência do movimento EscutAÇÕES.

\section{AS CONEXÕES E OS RESULTADOS PRELIMINARES DO MOVIMENTO DE EscutAÇÕES}

No período que compreende maio de 2020 a setembro de 2021, foram realizadas 7 lives internacionais, 23 lives nacionais - sendo que até novembro de 2021 objetiva-se cobrir todos os estados brasileiros - e 19 entrevistas, as quais compõem a série Educação Digital em Rede em tempos de pandemia: diálogos nacionais e internacionais. Todo material está disponível no canal do Youtube do GPe-dU UNISINOS/CNPq. Essa série representa o primeiro movimento da pesquisa, o Movimento EscutAÇÕES, constituindo, assim, o primeiro território da pesquisa.

O primeiro episódio da série: Educação Digital em Rede em tempos de pandemia: Brasil e Portugal, aconteceu no dia 14 de maio de 2020 e deu início à Formação de professores de escolas municipais de Educação Básica, intitulada Educação OnLIFE: a cibricidade como espaço de aprendizagem, desenvolvida no âmbito do Projeto de Pesquisa A cidade como espaço de aprendizagem: Práticas pedagógicas inovadoras para a promoção da cidadania e do desenvolvimento social sustentável, financiada pela Fundação Carlos Chagas e Itaú Social. Na sequência, desenvolveu-se as demais lives nacionais, internacionais e as entrevistas.

No âmbito dos dispositivos lives nacionais e lives internacionais, as pistas encontradas foram organizadas nos seguintes domínios: Estratégias; Desafios, Investimentos; Formação de Professores; Família; Articulação com a Universidade; Políticas Públicas; Aprendizagens, Educação pós-pandemia.

No âmbito do dispositivo entrevistas, as pistas encontradas foram organizadas nos seguintes domínios: organização das atividades educacionais; o planejamento escolar, considerando a estrutura existentes da escola e do aluno; a reorganização do planejamento; as orientações recebidas; o acompanhamento e avaliação dos processos de ensino e aprendizagem; o desenvolvimento das TD nos processos de ensino-aprendizagem; as mudanças frente às TD pós-pandemia; as dificuldades encontradas.

Sobre as lives nacionais, das 23 já realizadas - agrupadas por região -, temos no momento da escrita deste artigo: $100 \%$ região sul; $88 \%$ Nordeste; $50 \%$ Sudeste; $100 \%$ Centro-Oeste; e 85\% Norte. Nessas sessões, tivemos a presença de 22 Secretarias Estaduais de Educação; 21 representantes da UNDIMExii e 20 pesquisadores das seguintes instituições: Universidade 
Estadual de Maringá (UEM); Universidade Estadual do Maranhão (UEMA); Instituto Federal do Amazonas (IFAM); Universidade Federal da Bahia (UFBA); Universidade Federal do Ceará (UFCE); Universidade Federal do Espírito Santo (UFES); Universidade Federal de Goiás (UFGO); Universidade Federal de Minas Gerais (UFMG); Universidade Federal de Mato Grosso (UFMS); Universidade Federal de Mato Grosso do Sul (UFMT); Universidade Federal do Para (UFPA); Universidade Federal de Pernambuco (UFPE); Universidade Federal do Piauí (UFPI); Universidade Federal do Rio Grande do Sul (UFRGS); Universidade Federal do Rio Grande do Norte (UFRN); Universidade Federal do Sergipe (UFS); Universidade de Brasília (UnB); Universidades Tocantins Estadual do Tocantins (UNITINS); Universidade La Salle UNILASALLE, Centro Universitário Municipal de São José (USJ).

As pistas mais significativas encontradas no domínio Estratégias foram: planejamento das ações que deveriam se desencadear frente à demanda apresentada; adiantamento de férias escolares; oferta de formação de professores de maneira emergencial para um melhor atendimento aos alunos; disponibilização de plataformas digitais, computadores, canais de TV com aulas, mídia impressa, rádio, entrega de materiais no espaço escolar ou em domicílio; criação de e-mail aos alunos e salas virtuais; ações que proporcionam o "acolhimento" ao aluno por parte de professores e Secretarias; oferta de acompanhamento das Secretarias quanto ao acesso dos alunos aos materiais e meios ofertados.

As pistas mais significativas encontradas no domínio Desafios foram: problemas de infraestrutura; a falta de acesso ou acesso precário a dispositivos tecnológicos digitais e conexão internet por parte dos alunos; desinteresse das operadoras de internet com alunos carentes; ausência de formação de professores para apropriação pedagógica das TD; problemas emocionais dos professores; a defasagem na aprendizagem e como disponibilizar um ensino simultâneo consistente; a necessidade em condensar e selecionar conteúdos e reforçar revisões; a priorização do emocional dos alunos, de forma a atendê-los e acolhê-los; o estabelecimento de parcerias; o acesso e cabeamento das escolas; oferta ao professor de um engajamento e protagonismo mais efetivo; a necessidade de mudança no papel do professor; a transposição das práticas pedagógicas da modalidade presencial para o Ensino Remoto Emergencial; o domínio e construção dos atos e documentos normativos para a família, professores e alunos.

As pistas mais significativas encontradas no domínio Investimentos foram: compras de computadores; acesso à internet; aquisição e adaptação de Ambientes Virtuais de Aprendizagem (AVAs), assim como das plataformas digitais, por exemplo, Google for Education e Microsoft for Education; compra de softwares e licença de aplicativos; logística de entrega domiciliar de material impresso.

As pistas mais significativas encontradas no domínio Formação de professores foram: necessidade de uma política pública e programa de governo efetivo de formação de professores no âmbito da Educação Digital; tomada de consciência sobre a insuficiência na formação docente; ausência de planejamento efetivo de formação; oferta imediata de treinamento e capacitação por parte das mantenedoras, tendo como base as demandas evidenciadas.

As pistas mais significativas encontradas no domínio Família foram: as famílias sem conhecimento para trabalhar as atividades escolares domiciliares; o acompanhamento inicial dos filhos seguido do abandono - pela volta ao trabalho -; falta de espaço adequado de estudo; 
preocupação da família com o processo de aprendizagem do filho; busca de outras formas como materiais didáticos - impressos ou salvos em um pen drive -; carência de equipamentos adequados; falta de máquinas em casa; serviço de internet ruim; adoção do aplicativo WhatsApp como recurso para realização da comunicação entre escola, família e estudante; familiares de alunos em Educação Infantil e classes de alfabetização com sentimento de abandono ou incapacidade; vulnerabilidade das famílias - redução do poder de compra, luto, dificuldades financeiras, ausência de políticas públicas de amparo, entre outros.

As pistas mais significativas encontradas no domínio Articulação com a Universidade foram: oferta de cursos pela universidade à Educação Básica; diálogo entre universidade e professores da Educação Básica frente às possibilidades tecnológicas digitais; trabalho das universidades com as TD não considerados pela Educação Básica; ausência de cooperação entre universidade e Educação Básica.

As pistas mais significativas encontradas no domínio Políticas Públicas foram a condução dada pelo Ministério da Educação no fomento e regulação da oferta de educação escolarizada em tempos de pandemia e a execução por parte dos governos estaduais e municipais no âmbito das políticas públicas, que resultou num avanço do terceiro setor aos recursos financeiros educacionais e, principalmente, no monopólio da empresa Google, das empresas de telefonias Claro, Vivo, Tim e de redes de televisão acerca do fornecimento de softwares, aplicativos, limites de banda de dados móveis, canais específicos para transmissão de videoaulas, disponibilizados para as redes educacionais no sentido de conectar ou estabelecer um contato digitalmente entre professores e alunos.

Quanto à parceria pública-privada, não seria um problema se fossem estabelecidos critérios objetivos, por meio de dispositivos legais, que permitissem um controle social e transparecessem a efetividade do alcance e eficácia do acesso de professores e alunos ao processo educativo. Todavia, em boa parte dos entes federados, não se tem claro, ou ainda explicitado nos documentos oficiosos consultados, a dimensão dos gastos e da sua efetividade para a aprendizagem de crianças e adolescentes.

As pistas mais significativas encontradas no domínio Aprendizagens foram: o digital não pode ser utilizado como substituição do presencial; a necessidade de reinventar o momento; nomeia-se a educação - remota, híbrida, etc., cada vez que se utiliza de um novo recurso; não se anula outro processo ao falar do digital - não é o "isto" ou "aquilo", mas é o processo educacional de ensino e de aprendizagem -; conceitos inerentes às formas de ofertas e modalidades equívocos conceituais -; necessidade e importância de conhecimento em legislação e políticas públicas; aprendizagens específicas sobre aspectos pedagógicos relacionados às tecnologias digitais.

As pistas mais significativas encontradas no domínio Educação pós-pandemia foram: necessidade de planejamento de ações que atendam às demandas deste período "póspandemia; a questão psicológica de alunos e professores devem ser considerados no retorno; questões financeiras abaladas das famílias; necessidade de uma proposta de formação de professores efetiva; maior investimento para atender e buscar amenizar as perdas educacionais no período da pandemia. 
As pistas encontradas e sistematizadas nos fornecem elementos para responder as questões iniciais, assim é possível dizer que, no que se refere aos principais problemas encontrados pela Educação em tempos de pandemia, destacaram-se: ausência de planejamento que fosse capaz de envolver docentes e comunidade escolar em face às expectativas e reais condições de consecução das aulas; equidade no acesso a dispositivos tecnológicos e digitais por professores, estudantes e famílias; ausência de processos formativos acerca do que seriam aulas on-line, síncronas, assíncronas, virtuais, educação a distância e suas metodologias. Essas e tantas outras questões de ordem social não se demonstraram como pontos centrais na pauta de governos estaduais e municipais, estes, por sua vez, optaram por processos centralizadores de gestão do ensino, regulando e controlando exacerbadamente tempos e espaços por meio de tabelas de conteúdos programáticos engessados; plataformas digitais unilaterais; listas de conteúdos e exercícios, gerando um descompasso entre ensino e aprendizagem na relação professores e estudantes e consequentemente um adoecimento da classe docente ao não corresponder às metas e programas estabelecidos.

No tocante às estratégias desenvolvidas em diferentes países e, principalmente, no Brasil, a fim de dar continuidade a educação em tempos de pandemia, é possível dizer que as estratégias se assemelham com as ofertas imediatas de ações pouco planejadas; aberturas de espaços digitais aos alunos, prontos e formatados pelas mantenedoras; entrega de materiais impressos; disponibilidades dos serviços das Big Techs, em especial, Google e Microsoft, mantidos pelos governos.

Sobre a maneira como os municípios, os Estados e as universidades brasileiras se mobilizaram, é possível afirmar que houve uma grande mobilização, por parte da Educação Básica - principalmente, em iniciar a oferta das atividades, o que imediatamente apontou a ausência de formação docente, assim como de uma cultura digital consistente frente às TD, além da carência de infraestrutura para a oferta. Percebe-se que as universidades, pelas características de seus alunos, tinham mais acesso aos equipamentos necessários e já estavam vivenciando experiências anteriores com as TD. As formações aos professores, ofertadas pelas secretarias, mostraram-se insuficiente neste momento. Essa mobilização foi em direção à oferta de propostas, ao período, e não em direção de possibilidades de garantia da aprendizagem.

No que se refere às aprendizagens e aos desafios que a pandemia trouxe para a pesquisa em Educação, é possível afirmar a necessidade de ampliar e adensar parcerias, bem como a de potencializar a cocriação de redes em que os pesquisadores possam compartilhar e discutir suas produções, e que essas produções venham a contribuir com o desenvolvimento de políticas públicas que contribuam efetivamente.

Os resultados acima apresentados evidenciam, cada vez mais, a urgência de uma escuta atenta e o fomento à realização de trocas e compartilhamento de vivências relacionadas aos processos de ensino e de aprendizagem, assim como de gestão educacional durante o período pandêmico e neste momento pós-pandêmico, articulando Redes de Educação Básica e universidades. Do mesmo modo, fornecem pistas importantes no que diz respeito a necessidades formativas, as quais precisam estar orquestradas em programas de formação continuada de professores. Tais resultados mostraram também a necessidade do desenvolvimento de políticas públicas, tanto no âmbito da formação docente quanto no âmbito de uma Educação Híbrida e 
Multimodal. Em especial, instigam-nos, ainda mais, a potencializar o processo de cocriação de um espaço comum, em que a construção em rede se efetive em propostas de formação docente, bem como de currículos, metodologias e práticas pedagógicas transubstanciadas e inventivas, capazes de fazer emergir a Educação OnLIFE.

\section{CONSIDERAÇÕES FINAIS}

Entendemos que a primeira ação que precisamos realizar, quando se trata de desenvolver uma Educação OnLIFE, é a escuta atenta. Sempre é complicado o momento em que nos deparamos com propostas educacionais prontas, em que tudo está definido a priori, organizado conforme uma receita a ser aplicada, mesmo sem saber quem são os envolvidos e quais as suas necessidades. Então, o nosso objetivo inicial com a criação da RIEOnLIFE foi ouvir como os estudantes, os pais ou responsáveis, os professores, as equipes pedagógicas, os gestores de diferentes níveis de educação e os pesquisadores se movimentaram neste período de pandemia e quais estratégias os municípios, Estados, universidades brasileiras e alguns países desenvolveram.

Durante essa escuta identificamos, especialmente no contexto brasileiro, que os principais problemas encontrados se referiram à desigualdade no acesso às TD e à conectividade, problema também identificado em outros países, mas em menor intensidade. Para esse problema, diferentes estratégias foram adotadas, as quais envolveram: campanhas de doação de equipamentos e propostas de wifi solidário, uso de material impresso, do rádio, canal de TV para transmissão das aulas etc.

Outro problema comum - a todas as regiões brasileiras e também a outros países - referese à ausência de formação dos gestores ao tratar da compreensão do que significa educar numa realidade hiperconectada e, por consequência, que tipo de estrutura e funcionamento as instituições precisam ter para ofertar educação nesse contexto. Assim, as estratégias em sua maioria se resumiram a propor o Ensino Remoto Emergencial, no qual os mesmos cursos, com a mesma estrutura e currículo foram transpostos dos espaços geográficos presenciais físicos para espaços digitais em rede.

Da mesma forma, outra dificuldade comum a todas as regiões brasileiras e a outros países se refere à falta de um conjunto de competências que possibilitam ao professor ter fluência técnico-didático-pedagógica, a fim de que desenvolva a docência com diferentes TDs, em rede. Esse problema se tornou ainda mais evidente na docência realizada no Ensino Remoto Emergencial, no qual as práticas, as metodologias, o plano de aula desenvolvidos na sala de aula geográfica presencial física foram transpostos para espaços digitais em rede.

Apesar disso, relacionado às competências, chamamos a atenção ao destaque que tem sido dado ao desenvolvimento de competências digitais, uma vez que essas só se tornam efetivas se estiverem conectadas às demais. Não é aplicando instrumentos em que o professor se autoavalia quanto às competências digitais que possui e, posteriormente, formando o professor em competências específicas, de forma isolada, que vamos ter a inovação que desejamos e precisamos na educação. Para que o professor possa efetivamente transformar e transubstanciar as suas práticas pedagógicas, as metodologias, os planos de aulas, os currículos, precisamos de 
um programa de formação ecossistêmico, que atue na rede que se estabelece pela conexão entre as competências específicas da área de conhecimento na qual o professor é formado: as competências didático-pedagógicas, as competências socioemocionais, as competências digitais, as competências do pensamento crítico, da colaboração, da cooperação, da comunicação, da criatividade e da inventividade. Essa formação precisa ocorrer para os professores dos diferentes níveis, desde a Educação Básica até a Pós-Graduação e, em nível de extensão, de forma continuada e em ação.

A pandemia evidenciou, ainda, a falta de políticas públicas para uma Educação que precisa se desenvolver numa realidade hiperconectada e também relacionada à formação docente. 0 fato que nos parece mais grave, no entanto, refere-se às instituições que se mantiveram alheia a todo esse processo, ou seja, que a partir da identificação do primeiro problema, que foi a desigualdade no acesso às TD e à conectividade, optaram por suspender por completo as atividades com estudantes.

Assim, compreendemos que a escuta sobre quais foram os principais problemas encontrados, bem como as estratégias desenvolvidas por municípios, Estados, universidades brasileiras e também por outros países no âmbito da Educação em tempos de pandemia primeiro movimento da pesquisa foi escuta atenta - nos permitiu desenvolver os outros dois movimentos da pesquisa denominados COnversAÇÕES e COMpartilhAÇÕES, cada um com as suas especificidades. Dessa forma, atingimos o nosso objetivo com esse artigo que foi apresentar uma estratégia que emergiu da pesquisa durante a pandemia, a Rede Internacional de Educação OnLIFE - RIEOnLIFE, cujo foco está na cocriação de uma rede ou plataforma de Educação OnLIFE, que conecta pesquisadores, gestores, equipe pedagógica, professores e estudantes para, a partir do conhecimento das diversas realidades educacionais brasileiras e internacionais, configurar um novo ecossistema conectivo de inovação na educação, processo evidenciado pelos três movimentos e que está em construção e, por fim, discutir o primeiro movimento, o de EscutAÇÕES.

\section{REFERÊNCIAS}

BERGSON, H. Matéria e memória. São Paulo: Martins Fontes, 1999.

DI FELICE, M. Net-ativismo e ecologia da ação em contextos reticulares. Contemporânea: Revista de Comunicação e Cultura, Salvador, v. 11, n. 2, p. 267-283, maio/ago. 2013. Disponível em: https://biblat.unam.mx/pt/revista/contemporanea-salvador/articulo/net-ativismo-e-ecologia-da-acaoem-contextos-reticulares. Acesso em: 20 set. 2021.

DI FELICE, M. Net-ativismo: da ação social para o ato conectivo. São Paulo: Paulus, 2017.

DI FELICE, M. Paisagens pós-urbanas: o fim da experiência urbana e as formas comunicativas do habitar. São Paulo: Annablume, 2009.

DI FELICE, M. Pós-complexidade: as redes digitais vistas a partir de uma perspectiva reticular. Entrevista Concedida a Moisés Sbardelotto. Revista IHU On-line, São Leopoldo, 13 nov. 2011. Disponível em: https://www.ihu.unisinos.br/entrevistas/500515-pos-complexidade-as-redes-digitais-vistas-a-partir-deuma-perspectiva-reticular-entrevista-especial-com-massimo-di-felice. Acesso em: 28 dez. 2021. 
DI FELICE, M.; TORRES, J. C.; YANAZE, L. K. H. Redes digitais e sustentabilidade: as interações com o meio ambiente na era da informação. São Paulo: Annablume, 2012.

DONNA HARAWAY - SF: String Figures, Multispecies Muddles, Staying with the Trouble. [S. I.: s. n.], 2014.1 vídeo (1h50min). Publicado pelo canal KIASualberta. Disponível em:

https://www.youtube.com/watch?v=Z1uTVnhIHS8. Acesso em: 20 set. 2021.

ESCÓSSIA, L.; TEDESCO, S. O coletivo de forças como plano de experiência cartográfica. In: PASSOS, E.; KASTRUP, V.; ESCÓSSIA, L. (orgs.). Pistas do método da cartografia: pesquisa-intervenção e produção de subjetividade. Porto Alegre: Sulina, 2009. p. 92-108.

FLORIDI, L. (ed.), The Onlife Manifesto: Being Human in a Hyperconnected Era. London: Springer Open, 2015. Disponível em: https://link.springer.com/content/pdf/10.1007\%2F978-3-319-04093-6.pdf. Acesso em: 28 set. 2021.

HARAWAY, D. Anthropocene, Capitalocene, Chthulhucene. Entrevista por Martha Kenney. In: DAVIS, H.; TURPIN, E. (orgs.). Art in the Anthropocene: Encounters Among Aesthetics, Politics, Environment and Epistemologies. London: Open Humanities Press, 2015. p. 255-270.

HARAWAY, D. Antropoceno, capitaloceno, plantationoceno, chthuluceno: fazendo parentes. Clima com Cultura Científica, v. 3, n. 5, p. 139-146, 2016b.

HARAWAY, D. Staying with the trouble: making kin in the Chthulucene. Durham, Londres: Duke University Press, 2016 a.

KASTRUP, V. A cognição contemporânea e a aprendizagem inventiva. In: KASTRUP, V.; TEDESCO, S.; PASSOS, E. (orgs.). Políticas da Cognição. Porto Alegre: Sulina, 2015. p. 91-110.

KASTRUP, V. Aprendizagem, Arte e Invenção. Psicologia em Estudo, Maringá, v. 6, n. 1, p. 17-27, jan./jun., 2001. Disponível em: https://www.scielo.br/j/pe/a/NTNFsBzXts5GHp4Zk8sBbyF/?lang=pt\&format=pdf. Acesso em: 26 fev. 2021.

MOREIRA, J. A.; SCHLEMMER, E. Por um novo conceito e paradigma de educação digital OnLIFE. Revista UFG, Goiânia, v. 20, n. 26, p. 1-35, jan., 2020. Disponível em: https://doi.org/10.5216/revufg.v20.63438. Acesso em: 10 ago. 2021.

MORIN. E. Introdução ao pensamento complexo. Porto Alegre: Sulina, 2011.

PASSOS, E.; BARROS, R. B. A cartografia como método de pesquisa intervenção. In: PASSOS, E.; KASTRUP, V.; ESCÓSSIA, L. (orgs.). Pistas do método da cartografia: pesquisa-intervenção e produção de subjetividade. Porto Alegre: Sulina, 2012. p. 17-31.

PASSOS, E.; KASTRUP, V.; ESCÓSSIA, L. (orgs.). Pistas do método da cartografia: Pesquisa-intervenção e produção de subjetividade. Porto Alegre: Sulina, 2009.

PASSOS, E.; KASTRUP, V.; TEDESCO, S. (orgs.). Pistas do método da cartografia: a experiência da pesquisa e o plano comum. Porto Alegre: Sulina, 2014.

PIRES, E. F. W. Entrevista com Massimo Di Felice. Teccogs: Revista Digital de Tecnologias Cognitivas, São Paulo, n. 13, p. 7-19, jan-jun. 2016. Disponível em: https://www4.pucsp.br/pos/tidd/teccogs/entrevistas/2016/edicao_13/teccogs13_entrevista01.pdf. Acesso em: 26 fev. 2021. 
SCHLEMMER, E. A cidade como espaço de aprendizagem: games e gamificação na constituição de Espaços de Convivência Híbridos, Multimodais, Pervasivos e Ubíquos para o desenvolvimento da Cidadania, 2020. Relatório de pesquisa, referente ao Edital: UNIVERSAL MCTI/CNPq No 01/2016. Número do Processo: 425903/2016-8. Disponível em: https://gpedu.com.br/a-cidade-como-espaco-deaprendizagem-games-e-gamificacao-na-constituicao-de-espacos-de-convivencia-hibridos-multimodaispervasivos-e-ubiquos-para-o-desenvolvimento-da-cidadania/. Acesso em: 09 set. 2021.

SCHLEMMER, E. et al. ECoDI: a criação de um Espaço de Convivências Digital Virtual. In: SIMPÓSIO BRASILEIRO DE INFORMÁTICA NA EDUCAÇÃO, 17., Brasília, 2006. [Anais...]. Brasília: SBIE, 2006.

SCHLEMMER, E. Gamificação em espaços de convivência híbridos e multimodais: uma experiência no ensino superior (cognição em jogos digitais). Projeto de Pesquisa. Edital MCTI/CNPQ/MEC/CAPES $n^{\circ}$ 43/2013. São Leopoldo, 2013.

SCHLEMMER, E. Projetos de aprendizagem gamificados: uma metodologia inventiva para a educação na cultura híbrida e multimodal. Momento-Diálogos em Educação, Rio Grande, v. 27, n. 1, p. 42-69, 2018.

SCHLEMMER, E.; DI FELICE, M. A qualidade ecológica das interações em plataformas digitais na educação. Revista Latinoamericana de Tecnología Educativa, Badajoz, v. 19, n. 2, p. 207-222, 2020. Disponível em: https://doi.org/10.17398/1695-288X.19.2.207. Acesso em: 09 set. 2021.

SCHLEMMER, E.; DI FELICE, M.; SERRA, I. M. R. S. Educação OnLIFE: a dimensão ecológica das arquiteturas digitais de aprendizagem. Educar em Revista, Curitiba, v. 36, e76120, 2020. Disponível em:

https://doi.org/10.1590/0104-4060.76120. Acesso em: 09 set. 2021.

SCHLEMMER, E.; MOREIRA, J. A. Ampliando conceitos para o paradigma de educação digital OnLIFE. Interacções, Santarém/Portugal, v. 16, p. 103-122, 2020. Disponível em:

https://revistas.rcaap.pt/interaccoes/article/view/21039. Acesso em: 09 set. 2021.

SCHLEMMER, E.; OLIVEIRA, L. C.; MENEZES, J. O habitar do ensinar e do aprender em tempos de pandemia e a virtualidade de uma educação OnLIFE. Revista Práxis Educacional, v. 17, n. 45, 19, 2021. Disponível em: https://doi.org/10.22481/praxisedu.v17i45.8339. Acesso em: 09 set. 2021.

SCHLEMMER, E. Gamificação em espaços de convivência híbridos e multimodais: design e cognição em discussão. Revista da FAEEBA-Educação e Contemporaneidade, v. 23, n. 42, 2014.

SERRES, M. A Grande Narrativa do Humanismo: a história da humanidade: um Conto Iniciático. Lisboa: Instituto Piaget, 2010.

SERRES, M. Atlas. Barcelona: Teorema, 1994.

SERRES, M. 0 contrato natural. Portugal: Instituto Piaget, 1990.

SERRES, M. Polegarzinha. Rio de Janeiro: Bertrand Brasil, 2013.

SERRES, M. Tempo de Crise. Rio de Janeiro: Bertrand Brasil, 2017.

\footnotetext{
' Financiada pela bolsa Produtividade em Pesquisa do CNPq, em desenvolvimento no Grupo Internacional de Pesquisa Educação Digital - GPe-dU UNISINOS/CNPq, em parceria com a Universidade Aberta de Portugal. ii Esta ação tem o apoio da Escola de Humanidades, do Programa de Pós Graduação em Educação e do Centro de Estudos Internacionais em Educação da UNISINOS.
} 
iii O GPe-dU foi criado em 1998 e cadastrado no CNPq em 2005. Está vinculado ao Programa de PósGraduação em Educação da UNISINOS que há onze anos mantém conceito 07 na CAPES, ou seja, trata-se de um programa de referência na área da Educação no Brasil.

iv Schlemmer et al. 2006.

v Schlemmer, 2013.

vi Schlemmer, 2014.

vii Di Felice, 2013; Di Felice, Torres e Yanese, 2012.

viii Kastrup, 2001; 2015

ix Passos, Kastrup e Escóssia (2009), Passos, Kastrup e Tedesco (2014)

x Schlemmer, 2018; Schlemmer 2020.

${ }^{x i}$ A cibricidadania é a cidadania que se constituiu nesse hibridismo entre diferentes espaços físicosgeográficos e digitais, portanto, num espaço cíbrido. Esse espaço cíbrido se refere a cibricidade, essa cidade que é constituída não somente pela geografia feita de átomo, mas por uma geografia feita de bit, que pela digitalização, transforma a cidade em informação, a qual pode se conectar a outras redes informacionais. xii O Distrito Federal, pela sua organização, não tem UNDIME. 